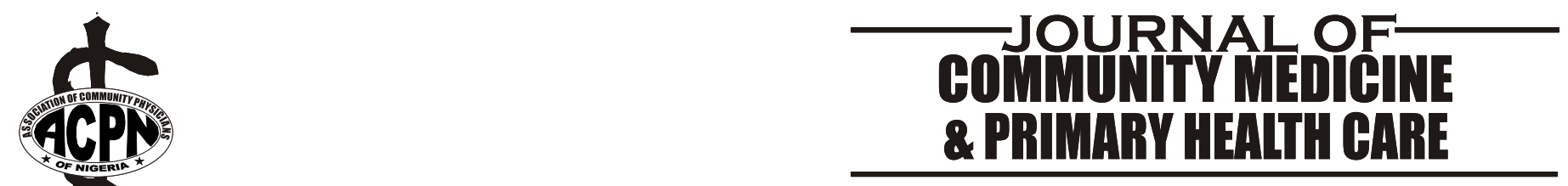

\title{
Maternal beliefs about infant teething
}

\author{
OG Uti ${ }^{1}$, KO Savage ${ }^{2}$ and EE Ekanem ${ }^{3}$ \\ ${ }^{1}$ Department of Preventive Dentistry, Lagos University Teaching Hospital, Idi-Araba, Lagos, Nigeria \\ ${ }^{2}$ Department of Preventive Dentistry, College of Medicine, University of Lagos, Lagos. Nigeria \\ ${ }^{3}$ Department of Community Health, College of Medicine, University of Lagos, Lagos. Nigeria
}

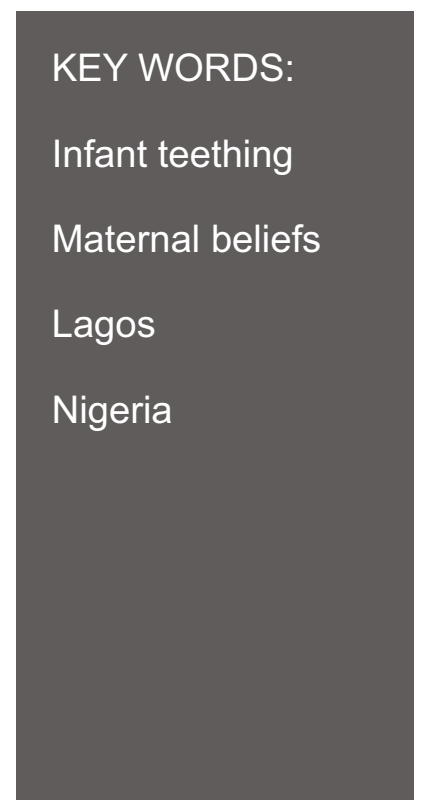

\section{Abstract}

Context and objective: Parents ascribe many symptoms to teething despite a lack of evidence to support such claims. A descriptive study of the perceptions of mothers on teething problems was conducted.

\begin{abstract}
Methods: Information was obtained on a consecutive sample of 333 mothers from an urban slum in Lagos state, Nigeria drawn from different socioeconomic, educational and ethnic backgrounds on their perceptions on teething problems.
\end{abstract}

\begin{abstract}
Results: The mean age of the mothers was 29.2 years and majority (52\%) were in the 20 -29 year age group. Most of the mothers $(95.2 \%)$ perceived teething to be associated with various symptoms while only $4.8 \%$ did not. The commonest problems reported were fever $(90.3 \%)$ and diarrhoea (87.3\%). There was no statistically significant association between perception of teething problems and education, age, and ethnic background. About half of the mothers viewed the symptoms as not serious and would not take the child to the hospital.
\end{abstract}

Conclusion: The beliefs and attitude of mothers about "teething" has serious implications for management of childhood fevers which may deserve urgent medical treatment. There is a need for early oral health education of mothers during the antenatal period to discourage the use of "teething as a ready explanation for childhood diseases.

\section{Introduction}

Eruption of teeth (teething) is defined as the movement of the teeth from their pre-eruptive position in the alveolar bone through the mucosa into the oral cavity'.

This process and its timing are of great interest to physicians, dentists and particularly parents who consider teething as an important event in their children's lives. It is therefore an event that is eagerly anticipated by both parents and child and has always been considered an important milestone in an infant's first year. Like most biological data, timing of eruption varies over a normal range $^{2}$. Teething generally begins around 6 months and continues until the baby is about 3 years old ${ }^{3}$.

Teething myths have existed in many cultures from early times. In1839, 5016 deaths in England and Wales were attributed to teething while 1600 deaths were recorded in $1910^{4}$

By 1918, some paediatricians asserted, "teething can give rise to serious symptoms" including "diarrhoea, vomiting, eczema, bronchial catarrh and convulsion as well as screaming fits and strabismus ${ }^{5 \prime}$. Although many of the conditions historically thought to result from teething are now accurately diagnosed as specific clinical entities, the enigma of teething continues, especially when a cause cannot be found for the many minor ailments a child experiences $^{6}$. According to current medical opinion, teething diarrhoea is a myth, yet cross-cultural data document a worldwide distribution of popular belief in the association of frequent loose stools with tooth eruption. ${ }^{7,8}$ 9.

A survey of Australian parents showed that only 1 of the 92 parents interviewed believed that teething causes no problems. Most parents (70 85\%) believed that teething causes fever, pain, irritability, sleep disturbance, mouthing/biting, drooling and red cheeks. While 35 55\% reported nappy rash, "soaking", ear pulling, feeding problems, running nose, loose stools and infections. A few parents $(<15 \%)$ reported smelly urine, constipation, colic or convulsions ${ }^{10}$. In Nigeria, a 1991 study reported that $58 \%$ of the respondents believed that teething might be accompanied by various local and systemic problems including, fever, diarrhoea and conjunctivitis ${ }^{11}$. This was supported by another study of ways through which adult health beliefs and attitudes affect their responses to the five major killer diseases during childhood in a Yoruba 
community in Nigeria. The study showed that "teething" and food related causes were believed to be responsible for diarrhoea ${ }^{12}$. The aim of this study was to determine the perceptions of Nigerian mothers on teething problems.

\section{Materials and methods}

Background: The study was carried out at Ajeromi Ifelodun Local Government of Lagos State, Nigeria, which could be described as a mini Nigeria because of its heterogeneous population. It is the most populous local government in Lagos State, with an estimated population of 1.24 million. This population comprises of a mixture of indigenous dwellers of Awori and Egun descendants as well as people from all parts of the country. Ajegunle, the headquarters of the local government is an urban slum. The local government has 11 wards, which for ease of medical administration are further divided, into seven health care districts. Adescriptive study was carried out at the seven primary health care centres, which are well located, and in close proximity to the people such that most mothers use the health centres for child welfare services and immunizations.

A consecutive sample of 333 mothers of infants from different ethnic backgrounds, socioeconomic classes and educational levels participated in the study. A standardized self-administered questionnaire was used for the literate mothers while the investigator marked questions for those who were illiterates after translating the questions into the appropriate language or Pidgin English.

\section{Analysis}

The collected data were analysed using the EPI info version 6.04 statistical soft ware. The chi square test of association was used where appropriate. Difference was taken as significant at the level of $P<0.05$.

\section{Results}

A total of 333 mothers participated in the survey. The mean age of the mothers was 29.2 years and majority $(52 \%)$ were in the $20-29$ year age group. Forty-one $(12.3 \%)$ mothers had no formal education, 95 (28.5\%) had primary school education, $140(42 \%)$ had secondary education, while $42(12.6 \%)$ had technical education and $15(4.5 \%)$ had university education.

Majority of the mothers (31.5\%) were traders, $29.4 \%$ were skilled workers, while 20.45 were housewives and only $3.3 \%$ were professionals.

\section{Perceived symptoms of teething}

Most mothers (95.2\%) associated teething with various symptoms such as diarrhoea, fever, vomiting, cough and weight loss, while only $4.8 \%$ did not. Most mothers $(90.3 \%)$ perceived that teething causes fever, $87.3 \%$ of the mothers believed teething causes diarrhoea, $88.5 \%$ believed it causes headaches, while $77.8 \%$ perceived that teething causes vomiting. Perceived teething problems are shown on Table 1

\begin{tabular}{lll}
\multicolumn{3}{l}{ Table 1: Perception of teething problems by mothers } \\
\hline Perceived problems & frequency & Percentage \\
\hline Fever & 268 & 80.5 \\
Diarrhoea & 213 & 64.0 \\
Headaches & 52 & 15.6 \\
Vomiting & 108 & 32.4 \\
Cough & 124 & 37.2 \\
Crying & 117 & 35.1 \\
Cold & 122 & 36.6 \\
Conjunctivitis & 20 & 6.0 \\
Weight loss & 111 & 33.3 \\
Drooling of saliva & 78 & 23.4 \\
Loss of appetite & 91 & 27.3 \\
Rashes & 10 & 3.0 \\
Convulsion & 6 & 1.8 \\
\hline
\end{tabular}

There was no significant association between age of mothers and perceived teething problems $(p=0.712)$. This is shown on Table 2 .

There was also no significant association between educational status and perception of teething problems ( $p$ $=0.816$ ) as well as the ethnic origin of the mothers

$(p=0.585)$. The perceived teething problems according to the educational level of mothers are shown on Table 3.

On the timing of the perceived problems associated with teething, $76.4 \%$ of the mothers reported having experienced the onset of symptoms in the children before teething started and $86.8 \%$ reported the end of the symptoms after the appearance of the tooth. This is shown on Figure 1.

On the attitude of mothers to teething problems, the symptoms encountered were perceived as serious by $52.3 \%$ of the mothers while $47.7 \%$ believed they were not serious and would not take the child to the hospital.

\begin{tabular}{|c|c|c|c|c|c|}
\hline $\begin{array}{l}\text { Age } \\
\text { (years) }\end{array}$ & NoProblems & Percentage & $\begin{array}{l}\text { Various } \\
\text { Problems }\end{array}$ & Percentage & Total \\
\hline$<20$ & 0 & 0.0 & 13 & 100 & $\begin{array}{l}13 \\
(100 \%)\end{array}$ \\
\hline $20-29$ & 8 & 4.6 & 165 & 95.4 & $\begin{array}{l}173 \\
(100 \%)\end{array}$ \\
\hline $30-39$ & 8 & 62 & 121 & 938 & $\begin{array}{l}129 \\
(100 \%)\end{array}$ \\
\hline $40-49$ & 0 & 0.0 & 13 & 100 & $\begin{array}{l}13 \\
(100 \%)\end{array}$ \\
\hline$>50$ & 0 & 0.0 & 5 & 100 & $\begin{array}{l}5 \\
(100 \%)\end{array}$ \\
\hline TOTAL & 16 & 4.8 & 317 & 95.2 & $\begin{array}{l}333 \\
(100 \%)\end{array}$ \\
\hline
\end{tabular}

\section{Discussion}

"Teething only produces teeth" is an adage used by many modern day paediatricians and dentists in an attempt to counteract the widely accepted belief of mothers that teething is associated with systemic upset. Findings from this study showed that a vast majority of mothers (95.2\%) 


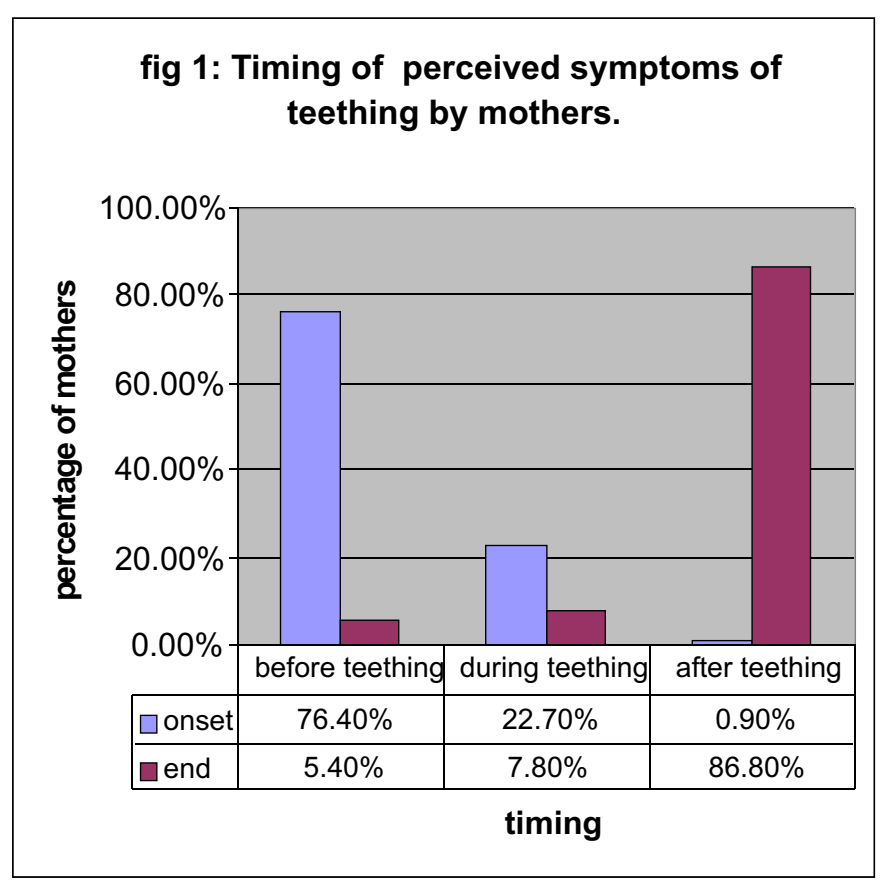

associated teething with various ailments or problems. The proportion is higher than (58.0\%) reported in an earlier study of teething myths in $1991^{11}$. In another study of perceived causes and management of diarrhoea in young children by market women in Enugu state, Nigeria, teething was perceived the major cause of diarrhoea by $69.8 \%$ $71.9 \%$ of the women ${ }^{13}$. The misconception is not only prevalent in Nigeria but also in other parts of the world. This finding is similar to the reports from Guinea Bissau ${ }^{14}$ and Ethiopia ${ }^{15}$. In Sudan, more than $90 \%$ of mothers believed that diarrhoea was caused by teething. ${ }^{8}$

The perception of teething problems is rather widespread as every strata of the study population irrespective of age, education, occupation or ethnic background reported it.

While Oyejide and Aderinokun reported a statistically significant association between educational status and perception of teething problems, the results of this study differ in that no such statistical association was found. This could be because of the difference in the samples.

Despite the fact that there is no agreement on the signs and symptoms of teething, and that several of the claimed features reported by mothers can be explained by alternative non-teething aetiologies, many mothers still testify that their children are teething. This is because of the transient nature and close temporal relationship of the features of teething to the pre, peri and post eruptive period of individual teeth. In this study majority of mothers associated onset of teething problems to the pre-eruptive period and the end of symptoms to the post eruptive period, a finding that is supported by Macknin et al who reported that teething was associated with an 8-day window: 4 days ${ }_{16}$ before, the day of, and 3 days after emergence of the tooth.

The attitude of mothers in this study has serious implications with respect to management of serious systemic symptoms. Diarrhoea and fever are regarded as normal phenomena that must accompany teething and are not viewed as serious enough to warrant medical attention. This is indeed worrisome as serious childhood illnesses, which are unrelated to teething, are likely to be left untreated or may not be given the seriousness they deserve.

In a household survey in Guinea Bissau, it was reported that children presenting with "teething diarrhoea" were less likely to receive oral rehydration salts (ORS) in the acute phase since "teething diarrhoea" is generally not considered serious ${ }^{14}$ These children are just as likely to become dehydrated as children presenting with diarrhoea developing from other causes or "non- teething" diarrhoea.

It is now accepted that the localised symptoms of teething vary between individuals, but severe systemic upsets are unrelated to teething and if present, the infant should be promptly referred to a physician for accurate diagnosis and treatment.

\section{Conclusion}

The study has shown that mothers in all socioeconomic classes, educational levels, age groups and ethnic background believe that teething causes ailments. There is need for a better recognition and understanding of the teething process and how to cope with whatever minor disturbances they may encounter. Improved dental health education will discourage the use of "teething" as a ready explanation for serious childhood diseases and ensure prompt attendance at hospitals for management.

\section{Table 3: Perception of teething problems according to educational level of mothers}

\begin{tabular}{lllllrl}
\hline Educational Level & \multicolumn{2}{l}{ Various problems } & \multicolumn{2}{l}{ No problems } & \multicolumn{2}{l}{ Total } \\
\hline None & 40 & $(97.6 \%)$ & 1 & $(2.4 \%)$ & 41 & $(100 \%)$ \\
Primary education & 90 & $(94.7 \%)$ & 5 & $(5.3 \%)$ & 95 & $(100 \%)$ \\
Secondary education & 132 & $(94.3 \%)$ & 8 & $(5.7 \%)$ & 140 & $(100 \%)$ \\
Post secondary & 40 & $(95.2 \%)$ & 2 & $(4.8 \%)$ & 42 & $(100 \%)$ \\
University & 15 & $(100 \%)$ & 0 & $(0.0 \%)$ & 15 & $(100 \%)$ \\
Total & 317 & $(95.2 \%)$ & 16 & $(4.8 \%)$ & 333 & $(100 \%)$ \\
\hline
\end{tabular}




\section{References}

1. Carpenter J V. The relationship between teething and systemic disturbances. ASDC J of child 1978; 45, 381 384.

2. Lawoyin $\mathrm{T} \mathrm{O}$, Lawoyin $\mathrm{D} \quad \mathrm{O}$, Lawoyin $\mathrm{J} \mathrm{O}$. Epidemiological study of some factors related to deciduous tooth eruption. Afri Dent J 1996; 10, 19 -23

3. Jones M. Teething in children and the alleviation of symptoms. J Fam Health care 2002; 12 (1): 12- 13

4. Registrar- General's $74^{\text {th }}$ Annual Report . Deaths from teething. London: HM Stationary Office, 1911-39

5. Burnet J. Conditions simulating disease which may be produced by teething. Br J child Dis 1918; 15:28

6. McIntyre G T, Mclntyre G M. Teething Troubles? B D J 2002; 192: 251-255

7. Coreil J, Price L, Barkey N. Recognition and management of teething diarrhoea among Florida paediatrians. Clin- pediatr Phila 1995; 34 (11):591 -8

8. Ahmed I S, Elton A R, Karrar Z A. Knowledge, attitudes and practices of mothers regarding diarrhoea among children in a Sudanese rural community. East Afr Med J 1994; 71(11): 716-9

9. Stapleton M C. Diarrhoeal diseases perceptions and practices in Nepal. Soc- sci Med 1998; 28(6):593-604

10. Wake M, Hesketh K, Allen M. Parent's beliefs about teething: A survey of Australian parents. J Paediatr child-Health 1999; 35(5): 4469
11. Oyejide $\mathrm{C} O$, Aderinokun $\mathrm{G}$ A. Teething myths in Nigerian rural Yoruba communities. Afr Dent J 1991; 5: 3134

12. Adetunji J A. Response of parents to five killer diseases among children in a Yoruba community, Nigeria. Soc-sci-Med 1991; 32(12): 1379

13. Ene Obong $\mathrm{H} \mathrm{N}$, Iroegbu $\mathrm{C} \mathrm{U}$, Uwaegbute A C. Perceived causes and management of diarrhoea in young children by market women in Enugu state, Nigeria. J Health popul nutr 2000; 18(2):97 -102

14. Sodemann M, Jakolosen M S, Molbak K, Martins C, Aaby P. Management of childhood diarrhoea and use of oral rehydration salts in a suburban West African community. Am J Trop Med Hyg 1999; 60(1):167-71

15. Olango P, Abond F. Determinants of mothers treatment of diarrhoea in rural Ethiopia. Soc-sci-Med 1990; 31(11); 1245-9

16. Macknin M L, Piedmonte M, Jacobs J, Skibinski C. Symptoms associated with infant teething: A prospective study. Pediatrics 2000; 105: 747752

17. Sodemann M, Jakolosen M S, Molbak K, Martins C, Aaby P. Maternal perception of causes, sign and severity of diarrhoea in a suburban West African community. Acta Paediatr 1996; 85(9): 1062-9. 